\title{
The Earth in Nature
}

\author{
The first issue of Nature was published 150 years ago, on the 4th of November 1869. In celebration of the \\ anniversary, we highlight some of our favourite geoscience stories from the archives.
}

S ome of the geoscience topics that Nature covered as early as the nineteenth century still resonate today. The "inconvenience and expense" caused by air pollution was highlighted in Nature's news section ${ }^{1}$. But the scope of the 1890 piece was limited to "The darkness of London air"; today the health impacts of pollution are still on people's minds, albeit now on a global scale ${ }^{2}$. Similarly, the devastating eruption of Krakatau volcano, reported $^{3}$ in Nature in 1883, continues to feature, for example, in investigations of the climatic effect of volcanism ${ }^{4}$. Nature's century-and-a-half long archives host a plethora of ideas and discussions that have not ceased to be relevant.

The plate tectonics revolution of the 1960s is a highlight. Several of the components that were to consolidate this framework of thinking, built on Wegener's hitherto rejected ideas of continental drift, came together in the pages of Nature in the course of just a few, exciting years. Following on from the discovery of the rift valley within in the Atlantic midocean ridge $\mathrm{e}^{5}$, the understanding of plate tectonics evolved rapidly. The theory of sea-floor spreading at mid-ocean ridges was proposed ${ }^{6}$ in 1961. Support for these ideas came from the correlation of the ages of ocean islands with their distances from mid-ocean ridges ${ }^{7}$ and from evidence for reversals of the Earth's magnetic field ${ }^{8}$ that allowed the linear magnetic anomalies on the seafloor to be recognized as a record of seafloor spreading'. Finally, transform faults were identified in and between mid-ocean ridges and mountain belts and recognized to bound the rigid plates and record the relative plate motions ${ }^{10}$.

In the wake of these discoveries, the Wilson cycle - the idea that ocean basins close to form supercontinents, which then rift to open up new ocean basins and so forth - was proposed, initially for the Atlantic Ocean ${ }^{11}$. The realization that North Pacific plate boundaries are consistent with rigid-plate motion ${ }^{12}$ confirmed and completed the theory of plate tectonics on the present-day Earth in 1967. Yet the topic of plate tectonics more broadly is far from settled: the debate has moved on to the questions of when and how plate tectonics on Earth started ${ }^{13,14}$, and whether it exists on other bodies in the Solar System ${ }^{15}$.

\section{Quotes from the archives}

London darkness": "Apparently very little is being done to make matters better, whilst on the other hand a good deal is being done to make things worse; the countless chimneys of these numerous buildings [added to London] are permitted to belch forth volumes of sooty smoke, almost without any check whatever."

Krakatau eruption": "The details which have reached us during the past week of the terrible seismic manifestation at Java prove it to be one of the most disastrous on record. [...] It has altered the entire physical geography of the region and the condition of the ocean bed."

In palaeoclimate science, when it became clear that deep sea sediment cores can reveal the build-up and decay of ice sheets on land, and not just ocean temperature ${ }^{16}$, a new chapter for studying glacial-interglacial cycles arose. The international ocean drilling programs helped unlock the climate archives in seafloor sediments from 1969 onwards ${ }^{17}$. With the advent of deep ice cores in Greenland ${ }^{18}$ and Antarctica ${ }^{19}$, actual measurements of the atmospheric composition over time were added to the long temperature records. Together, they leave no doubt that atmospheric $\mathrm{CO}_{2}$ concentrations have been very closely linked to the Earth's climate for the time we can reconstruct with confidence, which now goes back in time over eight glacial cycles ${ }^{20}$. These observations form one important cornerstone of our understanding of modern climate change.

The Antarctic ozone hole is another story that was partly written in past pages of Nature. The mechanism for the destruction of the Earth's stratospheric ozone layer was presented $^{21}$ in 1974, and the existence of an ozone hole over Antarctica was confirmed a decade later ${ }^{22}$. Despite the 1987 Montreal Protocol that banned the emission of anthropogenic ozone-depleting substances, ozone recovery is still being debated ${ }^{23}$, and has, indeed, encountered new challenges ${ }^{24}$.

A reflection on the geoscience archives of Nature reminds us of the enormous leaps in understanding that were made in the Earth
Seafloor spreading": "While the thought of a highly mobile sea floor may seem alarming at first, it does little violence to geological history."

Deep sea sediment cores $^{16}$ : It is simply necessary that every faunal or isotopic curve be re-read, taking 'cold' to mean 'extensive continental glaciation' and 'warm' to mean 'glaciers reduced to their present level"'

Eight glacial cycles ${ }^{20}$ : “Our results may imply that without human intervention, a climate similar to the present one would extend well into the future."

sciences. At the same time, the archives present a stark reminder that perturbations to our planet, including those caused by human activity, are often difficult to reverse. We must devote our ingenuity and effort towards stewardship of the Earth.

Published online: 31 October 2019

https://doi.org/10.1038/s41561-019-0488-2

References

1. Raffles, W. H. Nature 43, 152-153 (1890).

2. Lelieveld, J., Evans, J. S., Fnais, M., Giannadaki, D. \& Pozzer, A. Nature 525, 367-371 (2015)

3. Nature 28, 443-444 (1883).

4. Gleckler, P. J. et al. Geophys. Res. Lett. 33, L17702 (2006).

5. Heezen, B. C., Tharp., M. \& Ewing, M. Geol. Soc. Am. Spec. Pap. 65, 1-122 (1959)

6. Dietz, R. S. Nature 190, 854-857 (1961).

7. Wilson, J. T. Nature $197,536-538$ (1963).

8. Cox, A., Doell, R. R. \& Dalrymple, G. B. Nature 198 , 1049-1051 (1963)

9. Vine, F. J. \& Matthew, D. H. Nature 199, 947-949 (1963).

10. Wilson, J. T. Nature 207, 343-347 (1965).

11. Wilson, J. T. Nature 211, 676-681 (1966).

12. McKenzie, D. P. \& Parker, R. L. Nature 216, 1276-1280 (1967).

13. Weller, O. M. \& St-Onge, M. R. Nat. Geosci. 10, 305-311 (2017).

14. O’Neill, C., Marchi, S., Zhang, S. \& Bottke, W. Nat. Geosci. 10, 793-797 (2017)

15. Kattenhorn, S. A. \& Prockter, L. M. Nat. Geosci. 7, 762-767 (2014).

16. Shackleton, N. Nature 215, 15-17 (1967).

17. Nat. Geosci. 11, 801 (2018).

18. Grootes, P. M., Stuiver, M., White, J. W. C., Johnsen, S. \& Jouzel, J. Nature 366, 552-554 (1993).

9. Jouzel, J. et al. Nature 329, 403-408 (1987).

20. EPICA community members Nature 429, 623-628 (2004).

21. Molina, M. J. \& Rowland, F. S. Nature 249, 810-812 (1974).

22. Farman, C., Gardiner, B. G. \& Shanklin, J. D. Nature 315 , 207-210 (1985)

23. Chipperfield, M. P. et al. Nature 549, 211-218 (2017).

24. Fang, X. et al. Nat. Geosci. 12, 592-596 (2019). 